\title{
What is pulmonary fibrosis?
}

The origin of the term fibrosis lies in the histological observation of abnormal accumulations of collagen and other fibrous material thought to be secondary to injury or inflammation. In the light of recent advances in our understanding of the structure and metabolism of lung collagens and other components of the extracellular matrix, what had been a straightforward definition of pulmonary fibrosis has begun to look less satisfactory. Recent reviewers ${ }^{1-5}$ have been careful to qualify their definitions of pulmonary fibrosis to accommodate some puzzling experimental data.

Idiopathic pulmonary fibrosis (or cryptogenic fibrosing alveolitis) is classified as a fibrotic lung disorder due to an apparent increase in fibrous tissue within the alveolar interstitium. ${ }^{6}$ Recent biochemical studies of lung tissue obtained at biopsy, however, showed no increase in the amount of lung collagen in these patients. ${ }^{7}$ On the basis of this and other metabolic data the authors concluded that it was altered "quality, form and location" rather than the amount of collagen that was inportant. This conclusion was probably inappropriate since there are methodological problems associated with studies of biopsy material and the specimens obtained may not be representative of the whole lung (see refs 4 and 5 for reviews). Two independent studies of a large number of patients showed significantly increased collagen deposition, whether expressed as a concentration or as total content, in the lungs of patients with idiopathic pulmonary fibrosis. ${ }^{89}$ The conclusion drawn from the study by Fulmer and colleague, ${ }^{7}$ that there is an inappropriate distribution of collagen, is nevertheless important since remodelling of matrix components with deposition of bands of collagen in parenchymal regions normally characterised by thin basement membrane is a key feature of fibrotic lung disorders.

The interpretation of biochemical and histochemical data has been complicated by recent developments in connective tissue biochemistry. For example, there are now known to be at least 11 genetically distinct types of collagen and these may be identified individually by biochemical and immunological

Address for reprint requests: Dr J C Murray, Gray Laboratory, Mount Vernon Hospital, Northwood, Middx HA6 2RN. fingerprints. It is questionable whether standard histochemical techniques can distinguish between even two types of collagen, and measurement is notoriously difficult with these techniques. Changes to matrix components other than the collagens, particularly the proteoglycans, may alter the quality and number of binding sites available to standard histochemical stains, and this may confuse the issue. Some progress has been made with immunohistochemical markers for collagen. ${ }^{10}$ " In one study of idiopathic pulmonary fibrosis there was an increase in the ratio of type $I$ to type III collagen ${ }^{10}$ whereas in a second study changes in the reverse direction were seen." These differences may in part reflect the stage of disease at which samples were taken. ${ }^{12}$ The increasing availability of monoclonal antibodies to the different types of collagen, plus the application of in situ hydridisation techniques with probes to individual collagen types, should allow further progress to be made in the histological assessment of collagen.

Further biochemical developments have improved our understanding of the dynamic nature of lung collagen and normal fibroblasts, and have led to an appreciation that both the rate of degradation of collagen and the synthesis rate and number of fibroblasts play an important part in the regulation of lung collagen mass. Collagen synthesis is complex, with eight or more processing steps once the precursor molecules have been synthesised, with widely differing rates of turnover for newly synthesised and for mature collagens (see ref 5). There are few data on normal synthesis rates for pulmonary collagen in man and no general agreement on how they should be measured. There is indirect evidence of enhanced synthesis rates in idiopathic pulmonary fibrosis in man, however, ${ }^{1213}$ and synthesis rates are generally agreed to be increased in animal models of pulmonary fibrosis. ${ }^{4}$ Degradation is more difficult to measure and current evidence in man is contradictory. ${ }^{94}$ In animal models, where there is more information, the general pattern that has emerged suggests increased breakdown of extracellular collagen 1516 and decreased breakdown of newly synthesised collagen. ${ }^{14} 17$

These findings highlight another impediment to progress: the absence of valid experimental models for interstitial lung disease, particularly idiopathic 
pulmonary fibrosis. For some time research workers have relied on chemical injury induced by such agents as paraquat and bleomycin to mimic lung fibrosis in man, although the time course for the onset of such fibrosis is very short compared with the relatively slow, progressive course of most interstitial lung disorders seen in man. Radiation induced lung damage has a slower course in most species and may provide a better model, although even with this form of injury there appear to be differences in response, both quantitatively and qualitatively, between species $^{1819}$ and even strains. ${ }^{20}$

Some progress has been made in understanding the relationships between different types of cells in the lung, particularly those concerned with connective tissue metabolism. The availability of cells from bronchoalveolar lavage in recent years has made it possible to study putative mediators that may affect matrix and fibroblast function. Cells such as lymphocytes and mast cells have been implicated as sources of mediators, ${ }^{2125}$ and currently much attention is focused on the role of the alveolar macrophage as an important "effector" cell. Macrophages are capable of releasing at least two factors that may be relevant to the proliferation of mesenchymal cells observed in human interstitial lung disease-alveolar macrophage derived growth factor ${ }^{23}$ and platelet derived growth factor. ${ }^{24}$ Platelet derived growth factor has several actions, acting as a chemotactic factor for smooth muscle cells and fibroblasts and in addition as a "competence" factor, allowing various mesenchymal cells to respond to other "progression" factors, such as alveolar macrophage derived growth factor. In a study by Martinet $e t a P^{s}$ the spontaneous release of platelet derived growth factor by alveolar macrophages from patients with idiopathic pulmonary fibrosis was several times higher than that of control subjects, and this may explain the increased numbers of mesenchymal cells seen in idiopathic pulmonary fibrosis. The authors point out that platelet derived growth factor may be chemotactic for neutrophils, which are an important source of proteases and oxidants and are thought to be responsible for much of the destruction of parenchymal architecture. Other recent studies have suggested that clonal selection of mesenchymal cells might also operate. ${ }^{26}{ }^{27}$ Clearly progress is being made in this complex area, largely as a result of the application of the techniques of modern cellular and molecular biology.

Yet for connective tissue biochemists at least the original question posed in the title remains unanswered. In the words of Lewis Thomas, we must "wait for science to come in ... with the solid facts" ${ }^{\text {"28; }}$, then perhaps we can frame a new definition of fibrosis. The metabolic intricacies of fibrosis may appear irrelevant from the strictly clinical point of view when the radiographic appearances suffice to determine further treatment. Further advances in antifibrotic treatment $\stackrel{\mathcal{O}}{\sim}$ are unlikely, however, without a better understanding of the metabolic nature of this group of disorders. Current knowledge of collagen metabolism in normal $\frac{\bar{c}}{\partial}$

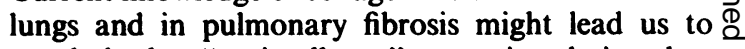
conclude that "anti-collagen" strategies, designed to inhibit collagen accumulation by interfering with one or more of the many post-translational modifications? required to produce the final mature fibril, is poten- $\overrightarrow{\vec{\omega}}$ tially hazardous, although this approach should still $\stackrel{\leftrightarrow}{\rho}$ be pursued. Rapid advances in our understanding $\vec{x}$ of cellular factors associated with injury, inflammation, and repair suggest that we should also consider taking several biochemical steps backward along the $\overrightarrow{0}$ fibrotic pathway in our search for new therapeutic 의 approaches.

\section{Cancer Research Campaign Gray Laboratory Mount Vernon Hospital Northwood, Middlesex HA6 $2 R N^{<}$}

G J LAURENT Cardiothoracic Institute London

\section{References}

1 Rennard SI, Crystal RG. Lung. In: Weiss JB, Jayson MIV, eds. Collagen in health and disease. Edinburgh: Churchill Livingstone, 1982:424-4.

2 Last JA. Changes in the collagen pathway in fibrosis. Fund Appl Toxicol 1985;5:210-8.

3 Witschi HP, Tryka AF, Lindenschmidt RC. The many faces of an increase in lung collagen. Fund Appl Toxicol 1985;5:249-50.

4 Laurent GJ. Biochemical pathways leading to collagen deposition in pulmonary fibrosis. In: Evered D, Whelan J, eds. Fibrosis. London: Pitman Medical Publications, 1985. Ciba Foundation Symposium No 114.

5 Laurent GJ. Lung collagen: more than scaffolding. Thorax 1986;41:418-28.

6 Crystal RE, Fulmer JP, Roberts WC, Moss M, Line BR, Reynolds HY. Idiopathic pulmonary fibrosis: clinical, N histologic, radiologic, physiological, scintigraphic, cytologic and biochemical aspects. Ann Intern Med $\triangle$ 1976;85:769-88.

7 Fulmer JD, Bienkowski RS, Cowan MJ, et al. Collagen concentration and rates of synthesis in idiopathic pulmonary fibrosis. Am Rev Respir Dis 1980;122: 289-302.

8 Kirk JME, DaCosta PE, Turner-Warwick M, Littleton RJ, Laurent GJ. Biochemical evidence for an increased and progressive deposition of collagen in lungs of patients with pulmonary fibrosis. Clin Sci 1986;70: 39-45.

9 Selman M, Montano M, Ramos C, Chapale R. Concentration, bio-synthesis and degradation of collagen in 
idiopathic pulmonary fibrosis. Thorax 1986;41:355-9.

10 Madri JA, Furthmayr H. Collagen polymorphism in the lung. An immunohistochemical study of pulmonary fibrosis. Hum Pathol 1980;11:355-65.

11 Bateman ED, Turner-Warwick M, Haslam P, AdelmannGrill BC. Cryptogenic fibrosing alveolitis: prediction of fibrogenic activity from immunohistochemical studies of collagen types in lung biopsy specimens. Thorax 1983;38:93-101.

12 Kirk JME, Bateman ED, Haslam PL, Laurent GJ, Turner-Warwick M. Serum type III procollagen peptide concentration in cryptogenic fibrosing alveolitis and its clinical relevance. Thorax 1984;39:726-32.

13 Anttinen H, Terho EO, Jarvensivu PM, Savolainen E-R. Elevated serum galactosylhydroxylysyl glucosyltransferase, a collagen synthesis marker, in fibrosing lung diseases. Clin Chim Acta 1985;3:3-8.

14 Laurent GJ, McAnulty RJ. Protein metabolism during bleomycin-induced pulmonary fibrosis in rabbits. In vivo evidence for collagen accumulation due to increased synthesis and decreased degradation of the newly synthesized collagen. Am Rev Respir Dis 1983; 128:82-8.

15 McAnulty RJ, Moores SR, Talbot BJ, Laurent GJ. Collagen metabolism in mice with ${ }^{239} \mathrm{PuO}_{2}$-induced pulmonary fibrosis. Biochem Soc Trans (in press).

16 Murray JC, Parkins CS. Collagen metabolism in mouse lung after $x$-irradiation. Radiat Res 1987;111:498-510.

17 Kehrer JP, Witschi $\mathbf{H}$. In vivo collagen accumulation in an experimental model of pulmonary fibrosis. Exp Lung Res 1980;1:259-70.

18 Gross N. Pulmonary effects of radiation therapy. Ann Intern Med 1977;86:81-92.

19 Pickrell JA, Mauderly JL. Pulmonary fibrosis. In: Pickrell JA, ed. Lung connective tissue: location, metabolism and response to injury. Boca Raton, Florida: CRC Press, 1981.

20 Down JD, Steel GG. The expression of early and late damage after thoracic irradiation: a comparison between CBA and C57B1 mice. Radiat Res 1983;96: 603-60.

21 Crystal RG, Bitterman PB, Rennard SI, Hance AJ, Keogh BA. Interstitial lung disease of unknown cause. Part I. Engl J Med 1984;310:154-66.

22 Crystal RG, Bitterman PB, Rennard SI, Hance AJ, Keogh BA. Interstitial lung disease of unknown cause. Part II. Engl J Med 1984;310:235-44.

23 Bitterman RB, Rennard SI, Hunninghake GW, Crystal RG. Human alveolar macrophage growth factor for fibroblasts: regulation and partial characterization. $J$ Clin Invest 1982;70:806-22.

24 Shimokado K, Raines EW, Madtes DK, Barrett TB, Benditt EP, Ross R. A significant part of macrophagederived growth factor consists of at least two forms of PDGF. Cell 1985;43:277-86.

25 Martinet Y, Rom WN, Grotendorst GR, Martin GR, Crystal RG. Exaggerated spontaneous release of platelet-derived growth factor by alveolar macrophages from patients with idopathic pulmonary fibrosis. N Engl J Med 1987;317:202-9.

26 Elias JA, Rossman MD, Phillips PD. Phenotypic variability among density-fractionated human lung fibroblasts. Am Rev Respir Dis 1987;135:57-61.

27 McSharry C, Jordana M, Hamish D, Kelly J, Newhouse I, Gauldie J. Procollagen gene expression by primary fibroblast lines derived from central and fibrotic lung tissue in humans. [abstract]. Am Rev Respir Dis 1987;135:A306.

28 Thomas L. The medusa and the snail. New York: Viking Press, 1979:19-26. 